\title{
Rehabilitation of the Doum Palm Trees Which Damaged by War Conflict in Khokha District in the Coastal Areas
}

ISSN: 2637-7659

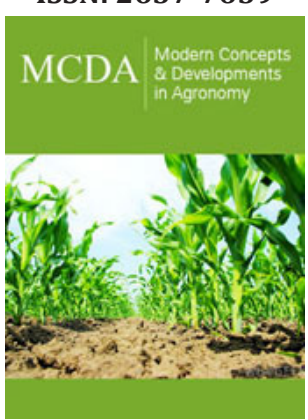

*Corresponding author: Abdo Bakri Ahmed Fakirah, Associateprofessor, Department of Agronomy and pastures, Faculty of Agriculture, Sana'a university, Yemen

Submission: 毗 December21, 2020

Published: 㘹January 08, 2021

Volume 7 - Issue 5

How to cite this article: Abdo Bakri Ahmed Fakirah. Rehabilitation of the Doum Palm Trees Which Damaged by War Conflict in Khokha District in the Coastal Areas. Mod Concep Dev Agrono. 7(5). MCDA. 000673. 2021. DOI: 10.31031/MCDA.2021.07.000673

Copyright@ Abdo Bakri Ahmed Fakirah, This article is distributed under the terms of the Creative Commons Attribution 4.0 International License, which permits unrestricted use and redistribution provided that the original author and source are credited.
Abdo Bakri Ahmed Fakirah*

Department of Agronomy and pastures, Faculty of Agriculture, Sana'a university, Yemen

\begin{abstract}
The protective effect of exogenous effectors applications against heavy metal toxicity in plants was investigated in this mini review. The exposure of plants to heavy metals caused high metal accumulation in tissues associated with increased levels of oxidative stress biomarkers as well as enhanced antioxidant enzymes. Hence, exogenous effectors were effective in reducing heavy metals-induced toxicity by maintaining the redox cell status.
\end{abstract}

\section{Summary}

Natural resources provide a substantial income for many rural households without which the ability of many households to satisfy their basic necessities of life would be threaten. Close links exist between natural resources and livelihoods of rural communities.

The doum palm Hyphaene the baica edible fruit, with common names Doum, Bahsh in Tehama and Tarie in Aden. these trees have been settled for hundreds of years near the coastal of Khokha district and other places in Hodiedah governorate.

The nature of the growth of these trees in their ecology included: high drought, salinity and heat tolerant, it also provides shade in the areas where it grows, so considered a crop horticulture. Leaves are probably the most important part of the doum palm, providing the raw material used in many products, and the fibers and leaflets are used by people along to weave baskets, beds ropes, hats.

The wood is occasionally used for firewood and charcoal but more often in construction, providing supports and rafters for houses, whereas root fibers are used for making fishing nets, seed inside the fruit is very hard and known as (Vegetable Ivory) is having been used commercially for making buttons and small carvings, fruit has a quite spongy wall that is very rich in carbohydrates and is a good source of iron and niacin. The mature nuts and kernels should be ground into meal as they are very hard. If used together with protein supplement, doum kernel meal is an excellent feed for all different animals that is comparable to maize. Doum palm trees are considered one of the occupational trees that generate income for families who work in them and improve livelihoods and food security.

\section{The Importance of the Different Parts of the Doum Palm Trees}

1. Whole doum palm tree is used in dune control and for shade, soil desertification protection and Preserving biodiversity in the surrounding environment

2. Leaves are probably the most important part of the doum palm, providing the raw material used in basketry, making mats, thatching, making string and in roofing, coarse textiles, and brooms. They are also browsed to a limited extent by livestock especially in dry periods. Leaves may also be used as fuel Wood (Figures 1-3). 
3. Wood is occasionally used for firewood and charcoal but more often in construction, providing supports and rafters for houses, posts for fencing and for building rafts. It can be cut by axe but is very difficult to saw due to the many fibers which make up the wood (Figure 4\&5).

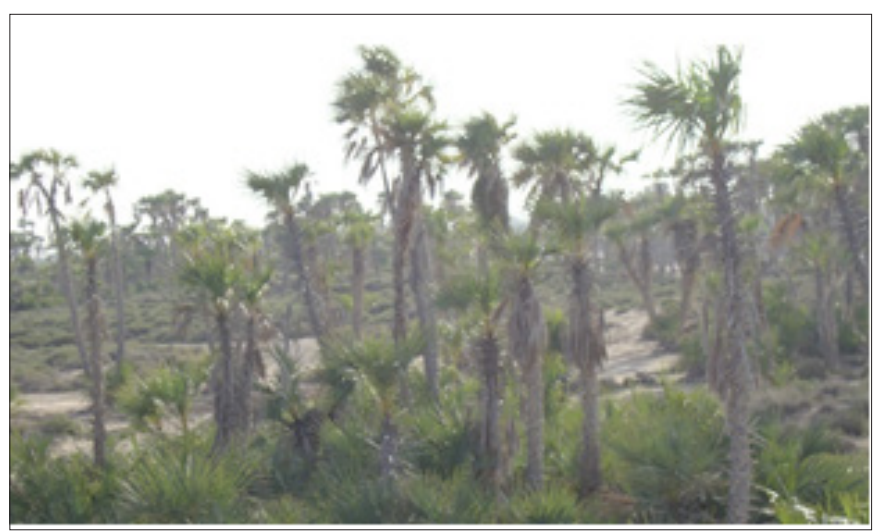

Figure 1: Doum palm trees in Tehama (Fakirah 2016).

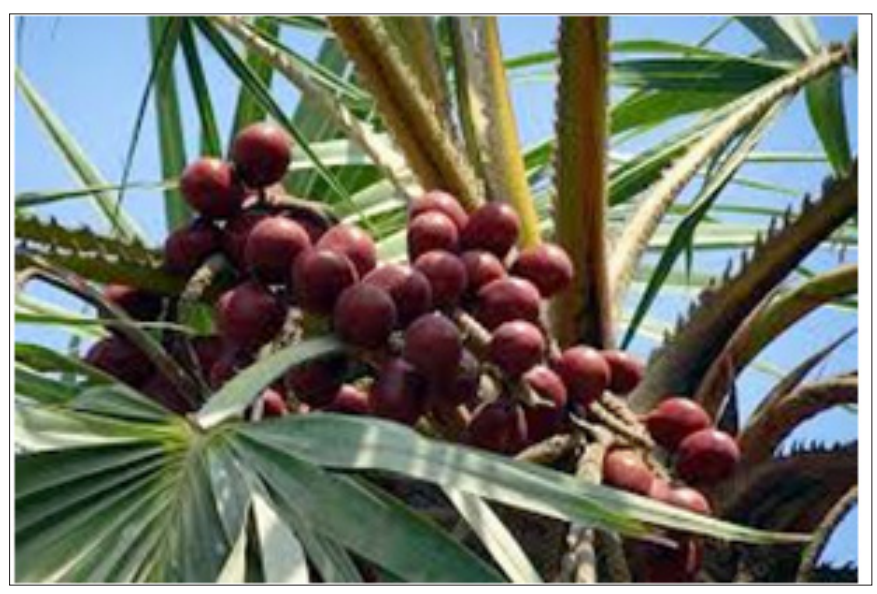

Figure 2: Doum palm tree carrying fruits.

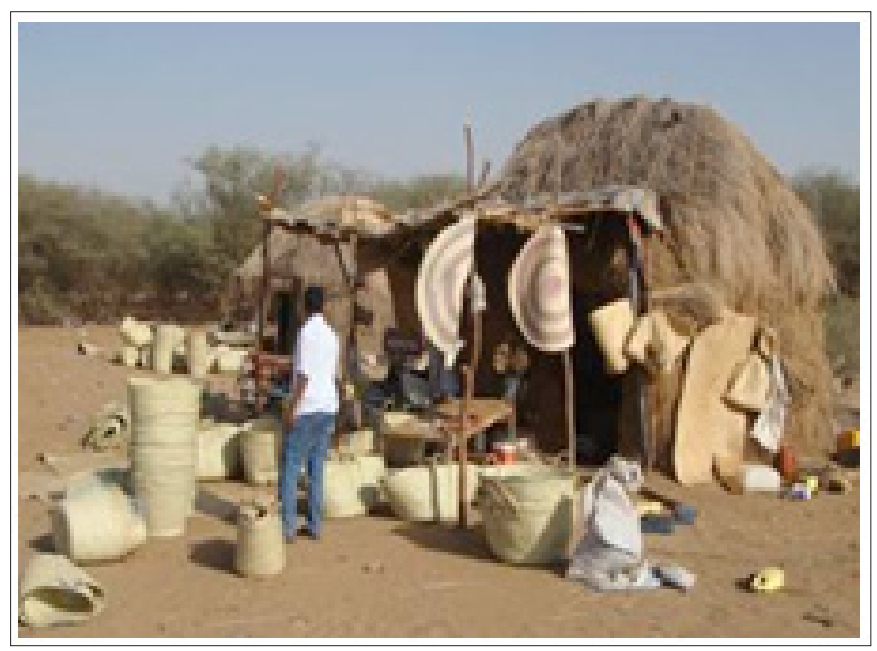

Figure 3: The products of Doum palm trees.

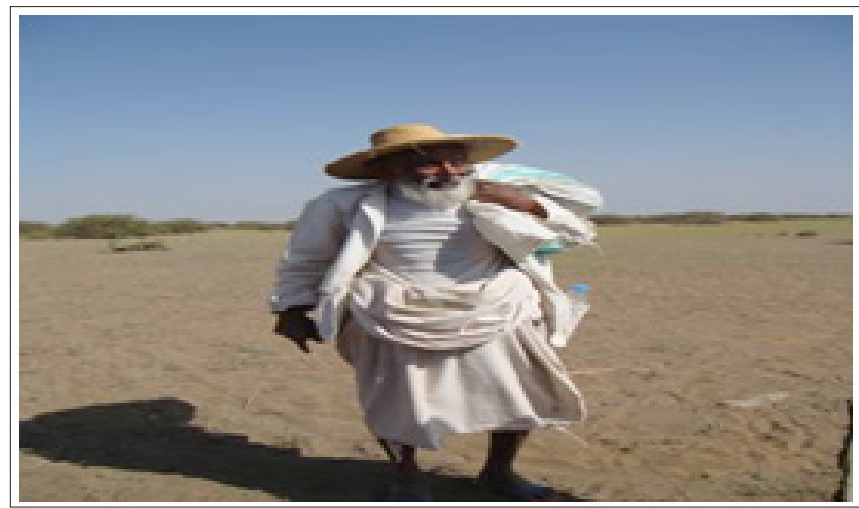

Figure 4: Man wearing hat made from doum palm plants.

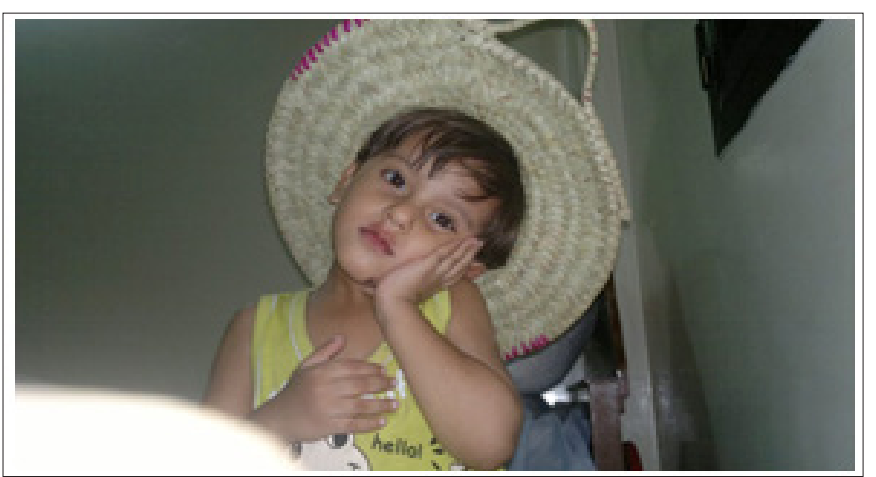

Figure 5: Child wearing hat made from doum palm plants (Fakirah 2016).

4. Root fibers obtained after 2-3 days of soaking and beating of the roots are used for making fishing nets. In local medicine roots are used in treatment of schistosomiasis.

5. Sap is used to make a black dye often applied on leather.

6. The covering of the fruits is edible and sharply aromatic (hence the name Gingerbread palm) and can either be pounded off to form a powder or cut off in slices. The powder from it is often dried and then added as a flavoring agent to food.

7. Seed inside the fruit is very hard and known as (Vegetable Ivory) is having been used commercially for making buttons and small carvings, but since the introduction of plastic, demand for this has dropped. Also, the sprouted seed is edible (palm cabbage) and the charcoal from the seed kernel is traditionally used to treat sore eyes in livestock.

8. Fruit has a quite spongy wall that is very rich in carbohydrates and is a good source of iron and niacin, also fruit pulp is chewed to control hypertension. It tastes like gingerbread and when soaked in water until the pulp becomes soft and syrupy is much enjoyed by children Sweet and bitter forms of the pulp are also known.

9. The mature nuts and kernels should be ground into meal as they are very hard. 
10. Doum kernel meal is an excellent feed for all different animals that is comparable to maize.

11. Nutritional Value: doum contained $7.0 \%$ ash, $15.0 \%$ crude fiber, $0.5 \%$ fat, $3.2 \%$ crude protein. Minerals were found to be $0.13 \%, 0.18 \%, 0.09 \%$ and $3.02 \%$ for $\mathrm{Ca}, \mathrm{Mg}, \mathrm{Na}$ and $\mathrm{K}$ respectively. Doum extract could be an important dietary source of phenolic compounds with high antioxidant and anticancer activities. Also, the pulp is known to have antioxidant properties, antimicrobial activity and can also be used in stabilizing food against oxidative deterioration.

\section{Doum palm trees colonies}

Along the western coast of Al Hodidah governorate, there are many colonies of doum palm trees, and this is reflected in the presence of communities that depend for their livelihood and mainly on these trees through finding handicrafts that depend on the products of the Doum palm trees and the effect of this on the maintenance and preservation of the Doum palm trees as they are their source of livelihood and food security.

\section{Role of Doum palm trees in family's livelihood}

1. Livelihood diversification plays an important role in improving food security

2. and income of people in rural areas.

3. The results revealed that primary source of income for majority of the Vulnerable and poor families

4. The income from Doum palm include all the income collected from selling of

5. Fruits sale and other products of Doum palm trees like baskets, beds ropes, hats.

6. Women play an important role in handicrafts relying on the Doum palm trees due to the ability of women to master these crafts such as basketry, making mats, coarse textiles, and brooms, and fishing nets.

7. The products of Doum palm were mostly prepared by the rural women at their homes.

Whereas the role of adults, girls and boys is limited to displaying handicraft products made from the various components of the doum tree plant in selling these products along the road in the West Coast at low prices that may be sufficient to sustain a living. and were either sold to local community or marketed in the urban centre.

\section{The role of doum trees in protecting the environment}

The presence of Doum tree palm colonies is accompanied by various types of natural pastures used to feed livestock, and these trees play an important role in protecting the lands in which they are located from the process of desertification, which prevents the formation of sand books in neighboring areas and main roads, as well as protecting the lands from the phenomenon of water erosion during the flow of torrents, And the protection of the wildlife present within the ecosystem in those colonies.

\section{Statement of the problem}

Doum palm tree is one of the most important trees in arid and semi-arid regions. It is considered as an important natural source of rural livelihoods in Khokha district., it is great Socio-economic concern as it also provides a wide range of products and services to local people in remote areas, by products of Doum palm are used extensively for both household and commercial purposes which provide substantial returns to rural people.

the role of Doum palm in sustainable livelihoods of farmers living in marginal areas of developing country.

More than five hundred families in Khokah district depend on Doum trees in their livelihoods and food security for decades, the number of Doum palm trees in Khokha district Approximately between $20000-30000$ trees.

As a result of manufacturing various products from the leaves, fibers and fruits of the Doum palm trees which started to generate income for families working with Doum palm tree products, although there are acute shortages of Doum trees due to the war previous crisis in the Khokha district.

Most of doum trees are damaged as a result of the air strikes and the existing war in the Red Sea coast, all families which used Doum trees in their livelihood lost their income, they became vulnerable families and many children from these families left schools to search for a living.

The war led to the loss of a large number of Doum trees as a result of the aerial bombardment and the presence of landmines and the effect of this on the environment of the Doum trees and their biodiversity, the emergence of indicators of desertification and the weak growth of salt-tolerant grazing plants in the Doum colonies and the effect of this on the process of grazing livestock and the livelihood of families working on Doum trees.

The Proposal was conducted to generate information role of Doum palm in improving livelihoods of rural people in Khokha district.

\section{Justifications}

1. Doum palm trees are considering national wealth and skill trees as compared with other plants.

2. Protection of Doum palm trees colonies from extinction

3. source of livelihood and food security for rural communities

4. protection of natural rangelands from Degradation.

5. Protection of livestock's from fodder shortage in the pasture. 
6. Poverty controlling for families which depend on the Doum palm trees in their livelihoods.

7. Combat desertification

8. Protecting children from dropping out of education due to the current crisis.

9. Doum palm trees are neglected crop.

\section{Objectives of the proposal}

Overall objective: Maintenance and protection of doum palm trees from extinction, sustainable of natural rangelands, preserving livestock, especially family-owned camels, in the vicinity of doum palm tree colonies, protecting families who have lost their livelihoods as a result of the current crisis and who rely on doum palm trees to provide their food security, and protect their children from dropping out of school to provide a livelihood, combat of soil desertification.

Specific objective: Conserve colonies of doum palms from extinction.

A. Rehabilitation of the doum palm trees that have been affected by the current crisis.

B. Rehabilitation of natural pastures tolerant of salinity and drought in the Dom colonies to preserve livestock.

C. Helping families working on doum palm trees before the current crisis and who lost their livelihoods to return to the handicraft industry based on doum palm trees and the impact of this on the return of their children to school.

\section{Methodology}

Site

1. Study will be conducted in four sites of Khokha district,

A. Doum ablam (lost most of Doum palm trees).

B. Al-mohrak (had few of Doum palm trees).

C. Al- madfa (There are medium numbers of doum palm trees).

D. Al-johypah (There are medium numbers of doum palm trees).
2. Study will comparise of both survey, rehabilitation, and replanting of the doum palm trees that have been affected by the current crisis.

\section{Field survey}

Survey will be conducted for all objectives one by administering a developed questionnaire to 125 selected rulers from each site with help of By the Khokha Association and the Local Council.

\section{Field experiment}

A. Rehabilitation of Doum palm trees by used some agricultural transactions (fertilization, Offshoot pruning, irrigation, Soil core,.)

B. Replanting of the doum palm trees by used methods propagation. (seeds, Offshoots)

\section{Treatments}

A. Nursery preparation

B. Farming seeds the interval between farming and seedling appeared 2-4 months.

C. Preparation of Seedling and transported to sustainable places

D. Farming seedling

E. Seedling fertilization with organic manure (10 tons/ 20000 seedling) or used urea (46\% N, 1000kg/ 20000 seedling) and super phosphate $(46 \%$ p2o5, $1000 \mathrm{~kg} / 20000$ seedling).

\section{Expected Output}

The expected results are

1. Will be support beneficiaries

2. Promotion of doum palm plants cultivation for being economical plants.

3. Promotion of doum palm plants products.

4. Rural people will win skill in the management systems the cultivation and manufacturing of doum palm plants products.

5. Increasing income rural people.

For possible submissions Click below: 